\title{
The Epidemiologic and Maternal and Fetal Prognosis of Teenage Girls
}

\author{
Leon Mubikayi \\ Christian Medical Institute of the Kasai, Kasayi University, Kasai, Democratic Republic of the Congo \\ Email: leonmubi@yahoo.fr
}

How to cite this paper: Mubikayi, L. (2020) The Epidemiologic and Maternal and Fetal Prognosis of Teenage Girls. Open Journal of Obstetrics and Gynecology, 10, 422-432.

https://doi.org/10.4236/ojog.2020.1030038

Received: November 27, 2019

Accepted: March 23, 2020

Published: March 26, 2020

Copyright $\odot 2020$ by author(s) and Scientific Research Publishing Inc. This work is licensed under the Creative Commons Attribution International License (CC BY 4.0).

http://creativecommons.org/licenses/by/4.0/ (c) (i) Open Access

\begin{abstract}
Objective: To identify the epidemiologic profile of the teenage mother; determine the frequency of teenage deliveries at CHME/Monkole; identify the most common obstetric complications during childbirth in adolescents; and evaluate the maternal and fetal prognosis of teenage birth in our environment. Methods: We conducted a descriptive study with a retrospective approach using records of teenage births admitted to the CHME/Monkole maternity between January 1, 2016 and December 31, 2017. Results: The overall rate of teenage delivery was $3.9 \%$. 2016 saw a high rate of $55.2 \%$. The average age was 18.2 years old, and the age group $17-19$ was the most affected. The commune of Mont-Ngafula had registered more cases than the other communes with $56.7 \%$. The majority of teenage girls who gave birth were primigravida (91\%). Urogenital infection was the most common pathology observed during antenatal care (ANC) visits in teenage pregnancies (25.4\%). Fetal-pelvic disproportion and water loss were the most common reasons for transfer, $15 \%$ each. Most pregnancies were completed (73.1\%). The delivery was eutocic in $55.2 \%$ of cases. The tearing of the soft tissues was the most encountered complication (7.5\%). Most newborns (83.6\%) had not received neonatal resuscitation in the delivery room. One case of maternal death was registered (1.5\%), and two cases of neonatal deaths were noted (3\%). Conclusion: Teenage pregnancy is a risk factor for childbirth. The most important risk is presented by a caesarean section following a bony pelvic dystocia and the tearing of the soft tissues during eutocic delivery. Educating young people about family planning remains important to prevent early pregnancies and thus promote girls' schooling.
\end{abstract}

\section{Keywords}

Childbirth, Teenage Girls, Caesarean Section 


\section{Introduction}

The adolescent birth rate is referred to as the age-specific fertility rate for women aged 15 to 19 years old.

Adolescent birth in the world and especially in poor and low-income countries remains a real public health problem because it has multiple consequences not only in the life of the adolescent mother, her child but also in society.

The situation remains alarming in the Democratic Republic of Congo (DRC) where most of the population is poor. It is, however, necessary to note that some traditions and customs, as well as degrading socio-economic conditions, favor early marriage among adolescent girls, sometimes resulting in unwanted teenage pregnancies.

According to the World Health Organization (WHO), nearly 16 million girls aged 15 - 19 give birth each year, and most of them in low- and middle-income countries. Complications from pregnancy and childbirth are the second leading cause of death among girls aged 15 to 19 years. Children of teenage mothers have a significantly higher mortality risk than those of women aged 20 to 24 . According to the same organization, teenage pregnancy remains one of the major contributors to maternal and child mortality and contributes to the cycle of poor health and poverty [1].

According to the United Nations Population Fund (UNFPA), a girl's pregnancy can change her life. She may be forced to drop out of school, which contributes to reducing her job prospects. She also becomes vulnerable to poverty and exclusion. Her health may also be affected: pregnancy and childbirth-related complications are one of the leading causes of death among teenage girls [2].

The drama of teenage mothers is lived differently in the world. This fact is closely linked to socio-economic conditions, accessibility or not to health services as well as to certain traditions and cultures of the region where the young teenage girl is from. The situation is still dire in poor countries where young adolescent girls are exposed to early marriages or enter into common-law relationships; and as a result, a marked increase in the number of teenage mothers. According to the WHO, in some societies young girls get married and start a family before the end of their own childhood. In other countries, most deliveries of young mothers take place outside of marriage, where there is a high rate of adolescent sexual activity, in some cases forced, or related to poverty and social exclusion [3].

The risks to the health of the mother and the baby are strongly associated with childbirth at an early age. The risk of dying from a birth-related harm is 2 times higher for adolescent girls aged 15 to 19 than for young women of older age; this is due to a variety of factors including first pregnancy, poverty, low social status and lack of access to health services [4]-[28].

What about our country, DRC, or even all around us? A question that is obviously worth asking, given a glaring lack of studies on this subject that seems to maintain the cycle of poverty in our environment. 
Thus, our study has set as a general objective to draw up the epidemiologic and clinical profile of teenage delivery at the Mother and Child Hospital Center/Monkole during the period going from January $1^{\text {st }}, 2016$ to December $31^{\text {st }}$, 2017.

As specific objectives:

$\checkmark$ Determine the rate of teenage delivery at CHME/Monkole;

$\checkmark$ Identify the most common obstetric complications encountered during adolescent childbirth;

$\checkmark$ Evaluate the maternal and fetal prognosis of adolescent childbirth.

\section{Patients and Methods}

We conducted a descriptive study with a retrospective approach using records of teenage births admitted to CHME/Monkole maternity between January 1, 2016 and December 31, 2017.

Included in the study were women who met the following conditions:

$\checkmark$ Having given birth at the maternity center of the Mother and Child Hospital Center/Monkole during the study period,

$\checkmark$ Being 13 to 19 years old,

$\checkmark$ Have a file containing our variables of interest.

All deliveries outside this criterion were excluded from the study.

We collected our data from maternity records, maternal records, and the CHME/Monkole computerized database.

The variables of interest collected were age, year, mode of admission, reason for transfer, marital status, obstetrical history, age of pregnancy at delivery, mode of delivery, newborn weight, the Apgar score, and neonatal resuscitation in the delivery room.

The descriptive statistics were used to calculate the means for quantitative data and the percentage for qualitative data.

\section{Results}

During our study period we identified 67 teen births out of a total of 1697 births, a rate of $3.9 \%$.

Table 1 shows that the age group of $17-19$ years was the most concerned in our study. The average age was 18.2 years with a standard deviation of 1.1, an age variation between 17.1 and 19.3 years.

The year 2016 had more cases with 37 (55.2\%) against 30 (44.8\%) for the year 2017 (Table 2).

We note that $70.2 \%$ had come to the hospital on their own (Table 3).

Table 4 shows that water loss and fetopelvic disproportion were the most common reasons for transfer.

Table 5 shows that $82.1 \%$ of teenage girls who gave birth were single.

We note in Table 6 that $91 \%$ of adolescent girls were primigravida.

We find that, of 67 teenage girls admitted to our series, only $28.4 \%$ of teenage girls had a normal-looking ANC (Table 7). 
Table 1. Age distribution of women.

\begin{tabular}{ccc}
\hline Age (year) & $\mathrm{n}$ & $\%$ \\
\hline $14-16$ & 6 & 9 \\
$17-19$ & 61 & 91 \\
Total & 67 & 100 \\
\hline
\end{tabular}

Table 2. Distribution of women by year.

\begin{tabular}{ccc}
\hline Year & $\mathrm{n}$ & $\%$ \\
\hline 2016 & 37 & 55.2 \\
2017 & 30 & 44.8 \\
Total & 67 & 100 \\
\hline
\end{tabular}

Table 3. Distribution of women based on the mode of admission.

\begin{tabular}{ccc}
\hline Mode of admission & $\mathrm{n}$ & $\%$ \\
\hline Came by themselves & 47 & 70.2 \\
Transfered & 20 & 29.8 \\
Total & 67 & 100 \\
\hline
\end{tabular}

Table 4. Distribution of women based on the reason of transfer.

\begin{tabular}{ccc}
\hline Reason of transfer & $\mathrm{n}$ & $\%$ \\
\hline Waterloss & 3 & 15 \\
Fetopelvic disproportion & 3 & 5 \\
Eclampsia & 1 & 10 \\
Hypertension & 2 & 10 \\
Non-tolerated anemia & 2 & 5 \\
Prematurity & 1 & 10 \\
Stationary labor & 2 & 5 \\
Head to the vulva & 1 & 5 \\
Prolonged pregnancy & 1 & 5 \\
Rape & 1 & 15 \\
Without transfer notes & 3 & 100 \\
Total & 20 &
\end{tabular}

Table 5. Marital status.

\begin{tabular}{ccc}
\hline Marital status & $\mathrm{n}$ & $\%$ \\
\hline Single & 55 & 82.1 \\
Married & 12 & 17.9 \\
Total & 67 & 100 \\
\hline
\end{tabular}

We note from this table that $73.1 \%$ of adolescents had carried their pregnancies to term and we recorded $22.4 \%$ of preterm deliveries (Table 8 ). 
Most teenage girls (55.2\%) had delivered vaginally. However, the rate of caesarean section in our series (44.8\%) is not to neglect (Table 9).

It appears from Table 10 that 7.5\% of adolescents had tearing of soft tissues.

Table 11 shows that $98.5 \%$ of teenage girls gave birth came out alive.

Most children (70.1\%) had a weight between 2500 and $3500 \mathrm{~g}$ (Table 12).

Table 13 shows that $86.5 \%$ of newborns had an APGAR score $>7$.

Table 14 shows that $16.4 \%$ of newborns received neonatal resuscitation in the delivery room.

Of a total of 67 births recorded 2 newborns were stillborn (3\%) compared to $65(97 \%)$ that were alive (Table 15$)$.

Table 6. Distribution of women based on their obstetrical antecedents.

\begin{tabular}{ccc}
\hline Antecedents & $\mathrm{n}$ & $\%$ \\
\hline Primigravida & 61 & 91 \\
Multigravida & 6 & 9 \\
Total & 67 & 100 \\
\hline
\end{tabular}

Table 7. Distribution of deliveries according to pathologies that occurred during pregnancy.

\begin{tabular}{ccc}
\hline Pathologies (ANC) & $\mathrm{n}$ & $\%$ \\
\hline Anemia & 5 & 7.5 \\
Urogenital infection & 17 & 25.4 \\
Hypertension & 3 & 4.5 \\
Threat of premature delivery & 5 & 7.5 \\
Paludism & 13 & 19.5 \\
PROM & 5 & 7.5 \\
None & 19 & 28.4 \\
Total & 67 & 100 \\
\hline
\end{tabular}

PROM: premature rupture of the membranes.

Table 8. Distribution of deliveries by age of pregnancy at delivery.

\begin{tabular}{ccc}
\hline Age & $\mathrm{n}$ & $\%$ \\
\hline $28-37$ LMP & 15 & 22.4 \\
$37-42$ LMP & 49 & 73.1 \\
$>42$ LMP & 3 & 4.5 \\
Total & 67 & 100 \\
\hline
\end{tabular}

Table 9. Distribution of teenage girls based on the mode of delivery.

\begin{tabular}{ccc}
\hline Mode of delivery & $\mathrm{n}$ & $\%$ \\
\hline Vaginal delivery & 37 & 55.2 \\
Abdominal delivery & 30 & 44.8 \\
Total & 67 & 100 \\
\hline
\end{tabular}


Table 10. Distribution of deliveries based on complications.

\begin{tabular}{ccc}
\hline Complications & $\mathrm{n}$ & $\%$ \\
\hline Antenatal haemorrhage & 2 & 3.0 \\
Postpartum haemorrhage & 4 & 6.0 \\
Tearing of soft tissues & 5 & 7.5 \\
No complication & 56 & 83.5 \\
Total & 67 & 100 \\
\hline
\end{tabular}

Table 11. Distribution of births by maternal evolution.

\begin{tabular}{ccc}
\hline Women & $\mathrm{N}$ & $\%$ \\
\hline Cured & 66 & 98.5 \\
Death & 1 & 1.5 \\
Total & 67 & 100 \\
\hline
\end{tabular}

Table 12. Distribution by birth weight.

\begin{tabular}{ccc}
\hline Weight & N & $\%$ \\
\hline$<2500 \mathrm{~g}$ & 15 & 22.4 \\
$2500-3500 \mathrm{~g}$ & 47 & 70.1 \\
$3500-4000 \mathrm{~g}$ & 4 & 6.0 \\
$>4000 \mathrm{~g}$ & 1 & 1.5 \\
Total & 67 & 100 \\
\hline
\end{tabular}

Table 13. Apgar score at the $10^{\text {th }}$ minute.

\begin{tabular}{ccc}
\hline Apgar score at $10^{\text {th }}$ minute & $\mathrm{n}$ & $\%$ \\
\hline$<3$ & 3 & 4.5 \\
$4-7$ & 6 & 9.0 \\
$>7$ & 58 & 86.5 \\
Total & 67 & 100 \\
\hline
\end{tabular}

Table 14. Distribution of newborns based on the need for resuscitation.

\begin{tabular}{ccc}
\hline Newborns & $\mathrm{n}$ & $\%$ \\
\hline Resuscitated & 11 & 16.4 \\
Not resuscitated & 56 & 83.6 \\
Total & 67 & 100 \\
\hline
\end{tabular}

Table 15. Distribution of cases by status of newborns at birth.

\begin{tabular}{ccc}
\hline Newborns & $\mathrm{n}$ & $\%$ \\
\hline Alive & 65 & 97.0 \\
Stillbirths & 2 & 3.0 \\
Total & 67 & 100 \\
\hline
\end{tabular}




\section{Discussion}

In our series, 67 cases out of a total of 1697 births registered at CHME/Monkole maternity hospital were teenage births, yielding a rate of 3.9\%. The year 2016 saw a high frequency of deliveries in adolescents (56\%) than 2017. This decreasing rate is influenced by several awareness campaigns on the prevention of early pregnancy and their consequences for adolescents' reproductive health organized by international organizations and the government, although this is not yet a won bet [29].

It is important to note, however, that adolescent studies pose age-limit problems according to the authors [23]. For some, the upper limit is 16 years, for others 18,19 or even 20 years. This makes comparisons relatively difficult. In our study, we considered the limits ranging from 13 to 19 years old.

Our results are different from those of a study by Mbemba Moutounou [30], from the Brazzaville University Hospital, on pregnancy and adolescent childbirth in Congo where the frequency was 5.3\% with an average age of 14 and 15 years. Another study, conducted in Lubumbashi, by Prosper Kakudji Luhete [31] found a frequency of $7.7 \%$. This could be explained by the less frequent use of contraception by the adolescent population; the precocity of sexual relations and early marriage ( $24 \%$ before the age of 15 ), the low level of education as well as the low level of education on sexuality.

The average age of adolescents giving birth at the Monkole maternity hospital was 18.2 years with a standard deviation of 1.1 years, which is a variation of age between 17.1 and 19.3 years. However, the age group of $17-19$ is the most represented with $91 \%$ as can be noted in Table 1 .

Our results are close to those of a study conducted in France in 2014 in the Department of Gynecology and Obstetrics at the Seine-Saint-Denis Hospital on the obstetrical and neonatal outcome of teenage pregnancies. In this study, Debras and Carbillon [18] found that the average age was 16.7 years, the most affected age group was between 17 - 19 years (86\%).

We noted in our study that $70.2 \%$ of adolescent girls who gave birth at CHME/Monkole came to consult by themselves while only $29.8 \%$ of adolescent girls were transferred [32].

We note in Table 4 that water loss and fetopelvic disproportion were the most common reasons for transfer, $15 \%$ each. Hypertension, not-tolerated anemia, and stationary labor accounted for $10 \%$ each. For other reasons, eclampsia, and prolonged pregnancy accounted for $5 \%$ of cases each.

We noted in our study that $82.1 \%$ of adolescent girls who gave birth were single compared to only $17.9 \%$ of married ones.

Our results are different from those found by Hamada et al. [33] in a study conducted at the Rabat Oranger Maternity in Morocco in 2004 on pregnancy and childbirth where a lower rate of unmarried adolescents was found (9.4\%). This situation could be explained by the fact that in Islamized societies girls are married very early, especially in rural areas, to preserve the virginity of girls. 
In our study, $91 \%$ of adolescent girls were primigravida.

Our results are in agreement with those presented by Hamada et al. [33], in a study in Morocco, where $10 \%$ of teenage girls were multigravida.

We noted that $25.4 \%$ of cases had urogenital infections during their ANC, followed by $19.5 \%$ of malaria and $7.5 \%$ of cases respectively for PROM, threat of premature delivery and anemia. Hypertension on pregnancy accounted for only $4.5 \%$ of cases and in $28.5 \%$ of cases pregnancy evolved normally. The high rate of urogenital infections could be explained by the hormonal action on the urinary tract but also by the pregnancy itself, which is one of the causes of the decrease of immunity in women [34].

In the literature, we find an anemia rate ranging from $11.1 \%$ for Osbourne to $34.9 \%$ for Konje. The urinary tract infection ranges from $5.9 \%$ according to Osbourne to $21.9 \%$ according to Janky. The arterial hypertension induced by pregnancy ranges from $3.5 \%$ according to Hardy to $20 \%$ according to Vinatier [34].

The study noted that $73.1 \%$ of adolescent girls had carried their pregnancies to term, followed by $22.4 \%$ who had a premature birth, and only $4.5 \%$ exceeded the term.

Our results are close to those found by Hamada [33], where $4 \%$ of adolescent girls were overtime. These data are contrary to a study conducted in France in 2012 by Malabarey et al. [34] who found a significant difference between delivery before $32 \mathrm{LMP}$ and $37 \mathrm{LMP}$ in adolescent girls compared to older women.

Debras et al. [18], however, in a study conducted in France drew the conclusion that prematurity was common among adolescent girls.

In our study, we found that $55.2 \%$ of adolescent girls had a vaginal delivery and $44.8 \%$ had an abdominal delivery.

A study conducted by Eure [35] found a high risk of caesarean section in adolescents while Jolly [36] found a reduction in cesarean section and obstetric maneuvers for adolescents under 19 when they were followed in a specialized environment.

Our study shows that $7.5 \%$ of adolescent girls had soft tissue tears, $6 \%$ had postpartum hemorrhage and $83.5 \%$ of cases had no complications.

The tearing of the soft tissues is due to the narrowness of the genital tract and leads to postpartum hemorrhage [27].

Monir Islam [37], director WHO's Department of Making Pregnancy Safer, said: Teenage pregnancies have common traits, still too young, organisms are not yet fully developed and cannot endure the adverse effects of the entire process of pregnancy and childbirth, and are at an increased risk of dystocia compared to women over 20 years of age. In the absence of emergency obstetric care, this leads to uterine rupture with a high risk of mortality. Among those who survive, the prolongation of the labor is at the origin of fistulas. He found that in Ethiopia $75 \%$ of women with fistula were pregnant before the age of 20 [38].

Regarding maternal mortality, in our study only one teenager (1.5\%) had died, yielding a maternal mortality rate of 1538 per 100,000 live births. 
Our results are different from those found in a study conducted by Djanhan and Souk [39] on adolescent childbirth at the Yopougon Teaching Hospital in Abidjan (Ivory Coast), which reveals an adolescent maternal mortality rate of 3326 per 100,000 deliveries. This could be explained by the efforts made by the CHME to reduce as much as possible the rate of maternal mortality through the continuous training of its medical staff, and the availability of a technical platform to ensure better care for these adolescent girls.

We note in Table 12 that $70.1 \%$ of newborns had a birth weight between 2500 - $3500 \mathrm{~g}, 22 \%$ of newborns had a birth weight lower than $2500 \mathrm{~g}, 6 \%$ had a higher weight between $3500-4000 \mathrm{~g}$, and $1.5 \%$ had a birth weight greater than $4000 \mathrm{~g}$.

Our results corroborate those of a study conducted in France in 2012 that found no significant difference between the birth weight in adolescent girls and the general population [18].

Our study shows that $86.5 \%$ of newborns had an APGAR score above 7 compared to only $4.5 \%$ with a score below 3 .

It should be noted that $16.4 \%$ of newborns had received neonatal resuscitation in the delivery room and 2 (3\%) of them were stillborn. This finding is similar to that found by Djanhan [39] at the Cocody University Hospital in Abidjan (Ivory Coast) in 2012, which found that $84 \%$ of newborns of adolescents were alive.

\section{Conclusions}

Childbirth in adolescent girls in poor, low-income countries remains a real public health problem because it has multiple risks and consequences in the life of the adolescent mother.

In our series, it represented a rate of 3.9\%; and the fetopelvic disproportion and water loss were the most common reasons for transfer, exposing the parturient to caesarean section, which was close to a non-negligible rate in our study (44.8\%).

The fetal prognosis was not particularly dangerous in our study, but it should be noted that $16.4 \%$ of newborns had benefited from neonatal resuscitation in the delivery room, a rate far from being negligible.

Thus, youth awareness on the need for a good family planning is of utmost importance to fight against this scourge.

\section{Conflicts of Interest}

The author declares no conflicts of interest regarding the publication of this paper.

\section{References}

[1] World Health Organization (2014) Teen Pregnancy. 364, 41-56.

[2] UNFPA. Teenager Pregnancies. http://www.unfpa;org/fr/grossesses-adolescentes

[3] Melntyre, P. (2007) Pregnant Teenagers: Delivering a Promise of Hope Worldwide. 
WHO, Geneva, 8-10.

[4] Merger, R., Levy, J. and Melchior, J. (1995) Specific Obstetrics. 6th Edition, Masson, Paris, 135.

[5] World Health Organization. Maternal, Newborn, Child and Adolescent Health. http://www.who.int

[6] The 2013 Youth Data Sheet. http://www.prb.org

[7] WHO. Prevent Early Pregnancy and Their Reproductive Health Consequences in Developing Countries.

[8] WHO (2005) Adolescent Health Guidance Program for Health Care Providers. Geneva, $5-10$.

[9] WHO (1995) Health and Development for Effective Programming. Geneva, 26-27.

[10] Marcellin, D. and Alvin, P. (2000) Pregnancies and Teenagers. Proceedings of the 2nd Day of Medicine and Adolescent Health, Poitiers, 9 December 2000, 105.

[11] Causes of Early Pregnancy.

[12] Sience, N., Pharisien, I. and Uzan, M. (2008) Teenage Pregnancy and Childbirth. Elsevier Masson, Paris, 211-228.

[13] International Plan: Causes and Consequences of Early Pregnancy. http://www.planinternational.org

[14] Jeanneret-EA Said (1983) Adolescents and Their Health. Paris, 2-6.

[15] UNICEF (2007) Demographic and Health Survey (EDS-DRC). Kinshasa, 51-53.

[16] Wagu, C.I. (2007) Maternal Mortality Factor in the Urban-Rural Health Area of Butembo, End-of-Cycle Memory. University of Graben, Graben-Butembo.

[17] WHO (2007) Pregnant Teenagers Deliver a Promise of Hope Worldwide. Geneva, 8-9.

[18] Debras, E., Bricoua, A., Carbillon, L., et al. (2014) Becoming Obstetrical and Neonatal of Teenage Pregnancies: Cohort of Seine-Saint-Denis Patients. 42, 579-584.

[19] Diane (2011) Birth among Teenagers at the Reference Health Center of Bamako Commune V. PhD Thesis, Bamako University, Bamako.

[20] Mulongo (2013) Epidemiologic Profile on Pregnancy and Childbirth in Teenage Girls, End-of-Cycle Memory. University of Kinshasa, Kinshasa.

[21] Combescure, C. (2007) Obstetric and Fetal Consequences of Teenage Pregnancy: Location in Nancy, Memory of DES, Gynecology-Obstetrics. Faculty of Medicine Nancy, Nancy, 47-56.

[22] Xenard, M.-E. (2000) Pregnancy and Maternity in Adolescence. PhD Thesis, Faculty of Medicine, Nancy.

[23] WHO (2007) Married Adolescent Girls. Geneva, 22-25.

[24] Soula, O., Carles, G., Largeaud, W., et al. (2006) Pregnancies and Childbirth among Adolescents under 15, Study of 181 Cases in French Guiana. Journal of Gynecology and Biology of Reproduction, 35, 53-61. https://doi.org/10.1016/S0368-2315(06)76372-4

[25] UNESCO (2013) Today's Youth, It Is Time to Act. Geneva, 18-35.

[26] Neuropsychiatrie of Childhood and Adolescence 63 (2015).

[27] Portier-le-Coq, F. (2009) Sexuality and Maternity of Adolescent Girls. Collection of Societies, Pur, Paris, 204-240.

[28] Mbantshi, P. (2016) Birth at School at the Hospital of the Friendship Sino-Congolese, Final Memory of Medical Study. UKA. 
[29] Benene, A., Elbernoussi, L., Elfarouqia, A., et al. (2009) Birth in Teenage Girls, Experience of Motherhood of Orangers (Rabat, Morocco), about 129 Cases. Maghreb Medicine, Electronic Edition, Rabat, 165, 50-54.

[30] Mbemba, G.-M., Iloki, L.-H., Koubaka, R., et al. (2004) Pregnancy and Childbirth in the Congo. About 276 Cases at the CHU in Brazzaville. Journal of Gynecology and Reproductive Biology, 33, 37-42. https://doi.org/10.1016/S0368-2315(04)96310-7

[31] Kakudji, P., Mwembo, O., et al. (2017) Maternal and Perinatal Prognostic Study during Childbirth in the DRC. Pan Africa Medical Journal, 28, 42-47.

[32] Faucher, P., Dappe, S. and Madelenat, P. (2002) Maternity in Adolescence: Obstetric Analysis and Review of the Influence of Cultural, Socio-Economic and Psychological Factors on a Retrospective Study of 62 Files. Gynécologie Obstétrique \& Fertilité, 30, 944-952. https://doi.org/10.1016/S1297-9589(02)00497-6

[33] Hamada, H., Zaki, A. and Taher, A. (2004) Teenage Pregnancy and Childbirth: Characteristics and Profile about 311 Cases in Morocco. PhD Thesis, 607-614.

[34] Malabarey, O.T., Swept, J., Klam, S., et al. (2012) Pregnancies in Young Adolescent Mothers: A Population-Based Study on 37 Million Births. Journal of Pediatric and Adolescent Gynecology, 25, 98-102. https://doi.org/10.1016/j.jpag.2011.09.004

[35] Eure, C.-R., Lindsay, M.-K. and Graves, W.-L. (2002) Risk of Adverse Pregnancy Outcomes in Young Adolescent Parturiants in an Inner-City Hospital. Journal of Obstetrics and Gynecology, 186, 918-920. https://doi.org/10.1067/mob.2002.123986

[36] Jolly, M.C., Sebire, N., Harris, J., et al. (2000) Obstetric Risks of Pregnancy in Women Less than 18 Years Old. Obstetrics and Gynecology, 96, 962-966. https://doi.org/10.1097/00006250-200012000-00018

[37] WHO (2009) Pregnancy in Adolescence: Complex Cultural Problem. Bulletin of the World Health Organization, 87, 405-484.

[38] Mboma, F. (2016) Childbirth at the Kintambo Reference General of Kintambo from 2010 to 2016, End of Study in Medicine. Technological University Bel Campus.

[39] Djanhan, Y. and Souk, M. (2012) Birth in Adolescence at Yopougon CHU in Abidjan. Specialization Dissertation, 23-26. 